\title{
When water gushed on Mars
}

Were the northern plains of Mars submerged in a vast flood as recently as 20,000 years ago? Geologists claim to have found evidence of a recent volcanic eruption under the ice cap that could have created a wall of water 200 metres high and 35 kilometres wide.

Signs of volcanic activity and flowing meltwater have been found before, but the new study links the two together with strong geological evidence, bolstering theories that water was the chief sculptor of the huge chasms in the northern martian ice cap. The flood, the researchers say, could have occurred within the past 10 million years and maybe as recently as 20,000 years ago - more evidence that Mars has not been a geological corpse since its wet and warm period billions of years ago.

Conditions in the time leading up to the flood - sulphur-rich volcanic gases, warmed water, an ice cap shielding against ultraviolet light - would have been similar to those at deep-sea vents on Earth that are crucibles for primitive life. "You have a set of conditions that comes close to what people have speculated would be favourable for life," says geomorphologist Niels Hovius at the University of Cambridge, UK, who led the study. "This would be a place where I would start looking."

The geology in this region of Mars is strikingly similar to features in British Columbia and in Iceland, where volcanoes and glaciers interact, says Hovius, who usually studies those environments. He began his martian venture with an image from the European Space Agency's Mars Express orbiter that

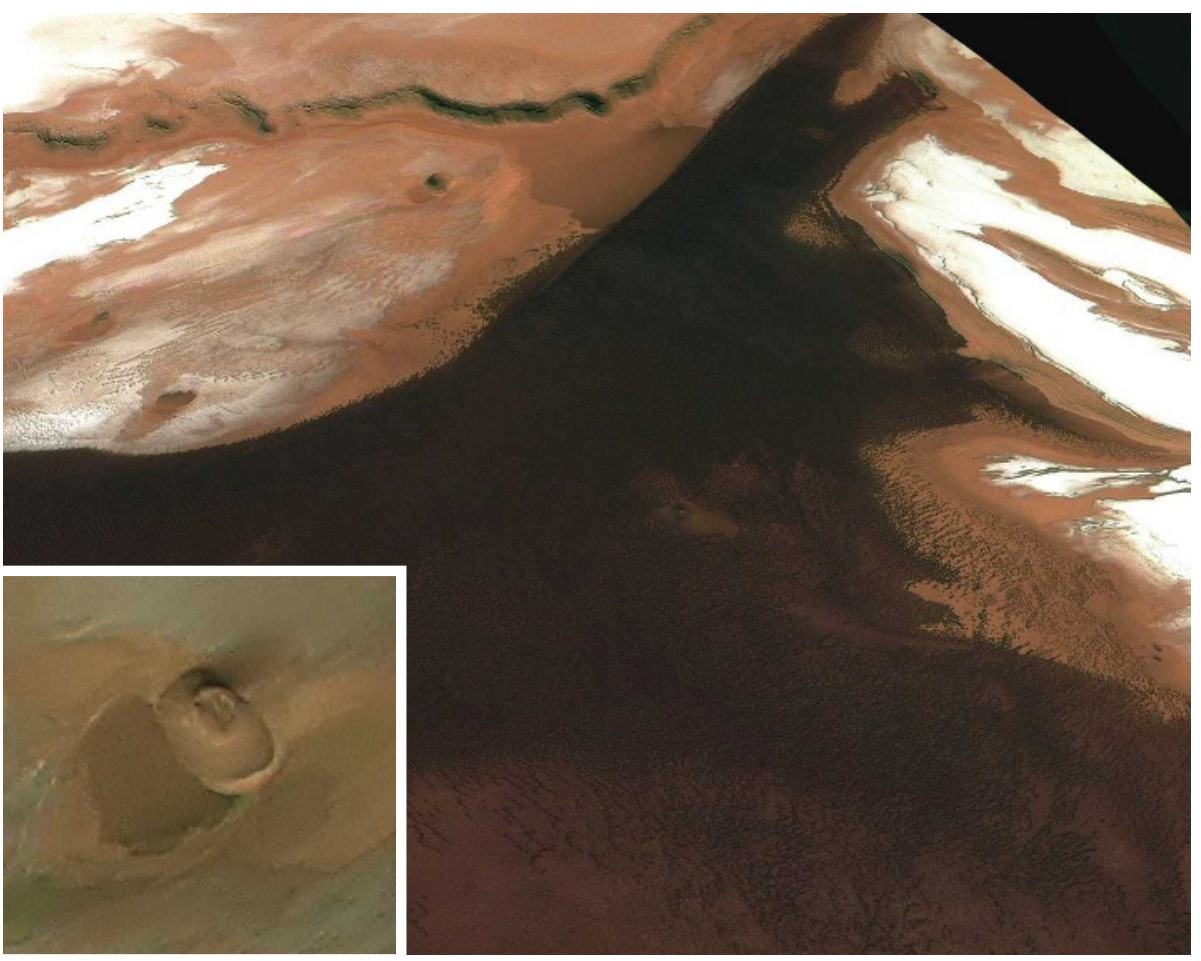

Basalt cones at the edge of the martian northern ice cap show evidence of flood scouring (inset).

chasms in the ice were started by water and perhaps later expanded by wind, says geologist Kathryn Fishbaugh at the Smithsonian Institution in Washington DC. "It's a strong paper," Fishbaugh says. "I think it's the best you can do for how melting might be triggered."

Fishbaugh says the only controversy about shows cones of basalt standing in a plain at the edge of the ice cap. Hovius noticed that the cones had material piled up on one side and scoured away on the other - like bridge piers in a river.

"The geomorphic evidence is screaming out that Mars has been active in relatively recent times."

That terrain leads to a chasm in the ice cap and then to a ring 6 kilometres across. Flattopped ridges extend outwards from the ring. Hovius's interpretation is that the ring is volcanic in origin (it is too deep in regard to its diameter to be an impact crater), and that the ridges are tuya, rock formed when lava erupts into ice. The amount of ice that could be melted by the mapped tuya matches the volume of 'missing' ice in an area of subsidence - in which the chasm lies - of several thousand square kilometres, Hovius says.

The study, which is in press in the journal Icarus, adds to the evidence that the many the study is the purported timing of the flood. The age of 10 million years is based on a lack of impact craters in the presumed flood area, but dates based on cratering records are notoriously uncertain. The 20,000-year estimate is even more speculative, being based on a blanket of dust observed on the ice cap, which Hovius attributes to detritus from the eruption. Fishbaugh, on the other hand, doesn't think that the chasm could have been eroded that quickly.

The flooding scenario could be confirmed with better images. Fishbaugh says the region is in the queue of high-resolution pictures to be taken by NASA's Mars Reconnaissance Orbiter by August. Meanwhile, the Phoenix lander, in the first month of its mission, sits in the northern plains on the other side of the ice cap (see Nature 453, 576; 2008). It is scraping through a thin layer of soil to the ice, as it attempts to unravel the area's history. If Phoenix finds evidence for recent melt water, the outburst floods could be a new mechanism providing it, says Victor Baker, a hydrologist at the University of Arizona in Tucson, who has proposed similar Mars flooding scenarios. Other explanations for any changes that Phoenix might find in the ice invoke changes in climate, caused by changes to Mars's tilt and orbit.

Even if Hovius's idea proves correct, there is still the question of what caused the volcanism in a seemingly inactive world. Just last month, researchers using radar on the Mars Reconnaissance Orbiter to peer through the ice cap found that the bedrock beneath was largely undeformed, unlike the warmer outer shell of Earth, which bends slightly under the overlying weight (R. Phillips et al. Science 320, 1182-1185; 2008). If the outer shell of Mars is so stiff and cold - even colder than the Moon, according to this study - how can hot material rise up from its interior? "It's typical Mars," says Baker. "We have a whole lot of things that seem to say that Mars is or should be dead. Yet the geomorphic evidence is screaming out that Mars has been active in relatively recent times."

Eric Hand 